\title{
Study of the composition and properties of vacuum coatings based on titanium carbide
}

\author{
Ravshan Saydaxmedov ${ }^{*}$, and Kutpnisa Kadirbekova \\ Tashkent State Transport University, Tashkent, Uzbekistan
}

\begin{abstract}
Carbide cutting tools are used for machining of machine parts made of complex alloyed materials. Application of protective composite nanostructured coatings on carbide cutting tools allows increasing the service life of cutting tools several times. The coating on their base protects the cobalt binding of carbide alloys. The low thermal conductivity of the composite nanostructured titanium carbide coating means that the heat generated when cutting workpieces is mostly transferred to the chips so that the tool does not become overheated. This is important when machining difficult alloyed, hard-to-machine, ductile materials for which the temperature at the contact zone of the cutting edge and the machined material reaches up to $900^{\circ} \mathrm{C}$. The adhesive interaction of the composite nanostructured coating with the substrate material is of no small importance in selecting the coating composition. From this point of view, carbide titanium coatings have good compatibility with carbide cutting tools. Along with this, the study of ion-plasma composite nanostructured coatings based on TiC carbides is relevant. The study results of the composition and properties of vacuum composite nanostructured coatings based on titanium carbides obtained by the ion-plasma method are presented. Studies of the chemical composition, the electronic and atomic structure of composite nanostructured coatings based on Ti carbides were carried out using the HREELS, XPS, and AES method and based on experimental studies of composite nanostructured TiC coatings, the $\mathrm{p}-\mathrm{T}$ $-\mathrm{x}$ diagrams for $\mathrm{TiC}$ were refined.
\end{abstract}

\section{Introduction}

Titanium carbide compounds, having high physic mechanical properties, are of great interest in connection with the possibility of application in various fields. In particular, materials based on titanium carbide are used in medicine to manufacture implants, in metallurgy in the preparation of dispersion-strengthened hard alloys, in the oil-producing and woodworking industry, and other industries. In [1], an analysis of the current state of production and use of titanium carbide was carried out. The authors considered the features of the production methods and application of titanium carbide in Russia and abroad.

Three groups are considered: 1. Powder metallurgy. 2. Spraying and surfacing of protective coatings. 3. Nanotechnology.

\footnotetext{
* Corresponding author: ravshansaid@mail.ru
} 
Powder metallurgy processes are based on the carbidization of titanium and the products of the carbothermic reduction of its compounds in bulk or compacted form in a nonoxidizing atmosphere $\left(\mathrm{N}_{2}, \mathrm{H}_{2}\right.$ vacuum, inert gas). Titanium carbide, produced by carbothermic reduction of its compounds in bulk or compacted form in a non-oxidizing atmosphere (nitrogen, hydrogen, vacuum, inert gas), is mainly used in powder metallurgy [2-7].

During the deposition and surfacing of protective coatings, carbidization of titanium and products from the carbothermic reduction of its compounds in the melt were used. Titanium carbide, obtained by carbothermic reduction of its compounds in the melt, is mainly used for spraying and surfacing protective coatings [8-10, 14, 16, 17].

In nanotechnology, carbidization of titanium and products from the carbothermic reduction of its compounds in the gas phase are used. Titanium carbide in the form of nanodispersed powders, obtained by carbothermic reduction of titanium compounds in the gas phase, is used in nanotechnology [18-24].

Some of the foreign producers of titanium carbide and carbonitride used the results of the research and production; in the United States: «Nanostructured \& Amorphous Materials. Inc, Ferro-TiC, in Germany, Deutsche Edeltahlwerke GmbH, Plama Chem Gmbh in China, Hefei Kaier Nanotechnology \& Development htd. Co», all of whom produce powders by various methods, the sizes of which were from 40-60 microns to 10$150 \mathrm{~nm}$.

Based on the analysis, the authors concluded that when using titanium carbide in the nanostate, there are new prospects for its use: surface modification of materials and modification of alloys [1].

The study of wear protection of cutting and technological tools and machine parts working in conditions of friction and in aggressive environments to which they are subjected is an urgent task. Composite nanostructured coatings on the surface of products to improve the performance characteristics based on titanium carbide and nitride make it possible to solve many of the most important technical problems.

The developed coating material must have a given set of properties that meet the basic requirements formulated to analyze the operating conditions of the tool.

The coatings on the cutting tool must have the following properties:

1)High adhesion to the tool material.

2)High hardness, exceeding the hardness of the tool material, retained at elevated temperatures.

3)Low adhesion to the processed material over the entire operating temperature range.

4)Stability of mechanical properties at temperatures not lower than the temperatures of heat resistance of the tool material.

5)Resistance to thermal fatigue, i.e., destruction at significant temperature and stress fluctuations.

6)Slight chemical interaction with air and other gases formed during the evaporation of cutting fluids (coolant) at elevated temperatures.

7)The optimal ratio of the main physical and mechanical, and thermophysical characteristics (modulus of elasticity, Poisson's ratio, thermal expansion, thermal and thermal diffusivity).

As a protective coating, the most widespread are carbides, nitrides, and carbonitrides of refractory metals of IV-VI groups of the Periodic Table of Elements. IV - includes titanium, zirconium, and hafnium; to V - vanadium, niobium, and tantalum; to group VI - chromium, molybdenum, tungsten.

Some carbides and nitrides of these elements have already found wide application; particularly, titanium nitrides are used as a wear-resistant coating for cutting tools. It is assumed that having such unique properties as high hardness is retained at elevated 
temperatures, chemical inertness to structural steels, corrosion resistance, etc. Some of them will find wide application as coatings.

Most transition metals have sufficiently large atomic radii and can obey the Hegg rule [24], according to which the ratio of the radius of a nonmetal atom to the radius of a metal atom $\mathrm{Rx} / \mathrm{Rm}$ should be less than the critical value of 0.59 . In this case, the implantation phases are characterized by a large region of homogeneity and, as a consequence, nonstoichiometry. The latter factors are of great importance since the properties of the interstitial phases substantially depend on the ratio of metal and nonmetal atoms. If the ratio $\mathrm{Rx} / \mathrm{RM}>0.59$, then compounds with a more complex structure are formed, which, as a rule, do not have regions of homogeneity.

Knowing the hierarchy of requirements for the coating material properties, it is necessary to choose a basic chemical element or an alloy of elements that satisfy the basic requirements as much as possible, i.e.; it is necessary to select the basis of the coating material. The task of synthesizing materials for protective coatings is reduced to the choice of alloying elements (metal and nonmetal) and the composition of the coatings (phase and chemical). When synthesizing coatings, it is important to correlate the structure and composition of a material with its properties, i.e., the development of quantitative regularities of the dependence of the properties of coatings on their chemical composition and structure $[25,26]$.

\section{Materials and Methods}

Composite nanostructured coatings based on titanium carbides were obtained by the ionplasma method in a vacuum unit NNV 6.6-I1. Coatings were applied to samples and cutting tools: drills and taps from high-speed steel R6M5. R6M5 steel is designed for all types of cutting tools in the processing of carbon and alloy structural steels, preferably for the manufacture of thread-cutting tools as well as tools operating with shock loads.

Studies of the chemical composition, electronic and atomic structure of composite nanostructured coatings based on titanium carbides were carried out using the HREELS method (spectroscopy of energy losses of high-resolution electrons), XPS (X-ray photoelectron spectroscopy), and AES (electronic Auger spectroscopy). The chemical composition of the tool material is shown in Table 1.

Based on the state and property diagrams and the $\mathrm{p}-\mathrm{T}$ diagram, it is possible to determine the optimum compositions of titanium carbide coatings and the corresponding process conditions for the selected composition through gas pressure and substrate temperature.

Table 1. Chemical composition of P6M5 alloy

\begin{tabular}{|c|c|c|c|c|c|c|c|c|c|c|c|}
\hline Material & \multicolumn{11}{|c|}{ Content of controllable impurities, $\%$, max. } \\
\hline & $\mathrm{C}$ & $\mathrm{Si}$ & $\mathrm{Mn}$ & $\mathrm{Ni}$ & $\mathrm{S}$ & $\mathrm{P}$ & $\mathrm{Cr}$ & Mo & $\mathrm{W}$ & $\mathrm{V}$ & Co \\
\hline P6M5 & $\begin{array}{c}0.82 \\
-0.9\end{array}$ & $\begin{array}{c}0.2 \\
- \\
0.5\end{array}$ & $\begin{array}{c}0.2- \\
0.5\end{array}$ & $\begin{array}{c}\text { until } \\
0.6\end{array}$ & $\begin{array}{c}\text { until } \\
0.025\end{array}$ & $\begin{array}{l}\text { until } \\
0.03\end{array}$ & $3.8-4.4$ & $\begin{array}{c}4.8- \\
5.3\end{array}$ & $\begin{array}{c}5.5 \\
- \\
6.5\end{array}$ & $\begin{array}{c}1.7 \\
- \\
2.1\end{array}$ & $\begin{array}{c}\text { until } \\
0.5\end{array}$ \\
\hline
\end{tabular}




\section{Results and Discussion}

For processing machine parts from complexly altered, difficult-to-machine materials by cutting, various cutting tools are used. The application of protective composite nanostructured coatings on carbide and other cutting tools considerably increases the durability of the cutting tool. The low thermal conductivity of the composite nanostructured titanium carbide coating contributes to the fact that the heat released during the cutting of parts is mainly transferred to chips; thus the tool does not heat up excessively.

This is important when processing complex, difficult-to-machine, viscous-plastic materials, for which the temperature in the zone of contact between the cutting edge and the material being processed reaches $900^{\circ} \mathrm{C}$. The adhesive interaction of the composite nanostructured coating with the substrate material is important when choosing a coating composition.

Therefore, carbide titanium coatings have good compatibility with hard alloy cutting tools. Along with this, the study of ion - plasma composite nanostructured coatings based on $\mathrm{TiC}$ carbides is relevant.

Titanium carbides have a wide area of homogeneity, i.e., the ability to form implantation solid solutions due to defects in the carbon and nitrogen sublattices (to form non-stoichiometric and superstoichiometric compounds - TiCx), which is very important when choosing composite nanostructured coatings from the point of view of controlling their properties relative to the material being processed. From this, it follows that the effect of nonstoichiometry on the structure and physicochemical properties of coatings is not well understood.

In setting the coating properties by varying its chemical composition and structure, it is possible to change the main compatibility parameters of the coating and the substrate as well as the characteristics of the exploitation process and control the most important parameters of the coating formation process.

These properties play a crucial role in the application of these compositions as wearresistant coatings on tool steels. When choosing a composite nanostructured coating composition, it is very important to combine the optimal values of several properties: hardness, thermal expansion coefficient, elastic modulus, thermal conductivity, etc. The range of properties of titanium carbide-based coatings can be significantly extended due to their homogeneity resulting from a defect in the carbon sublattice.

So titanium carbide of non-stoichiometric composition $\left(\mathrm{TiC}_{0.60}\right)$ has a high coefficient of thermal expansion, close to high-speed steel, and stoichiometric carbide - $\mathrm{TiC}_{1.0}$ has a high modulus of elasticity, hardness, and thermal conductivity.

From the perspective of optimality, physical methods are widely used to form functional coatings. In particular, coatings based on titanium carbides for hardening cutting tools and tooling have been obtained by the ion-plasma method.

Figures 1 and 2 show the photoelectron spectra of composite nanostructured carbide titanium coatings obtained at different acetylene pressures $-\mathrm{C}_{2} \mathrm{H}_{2}$. 


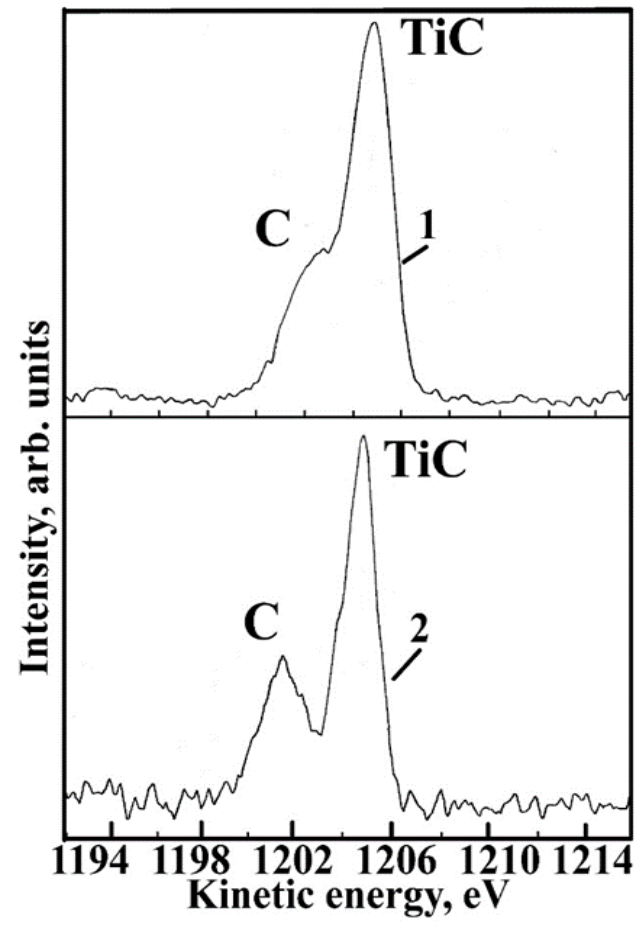

Fig.1- photoelectron spectrum of ion-plasma TiC coatings at different pressures $(\mathrm{P})$ of reactive gas: 1 $-0.004 \mathrm{~Pa} ; 2-1.06 \mathrm{~Pa}$

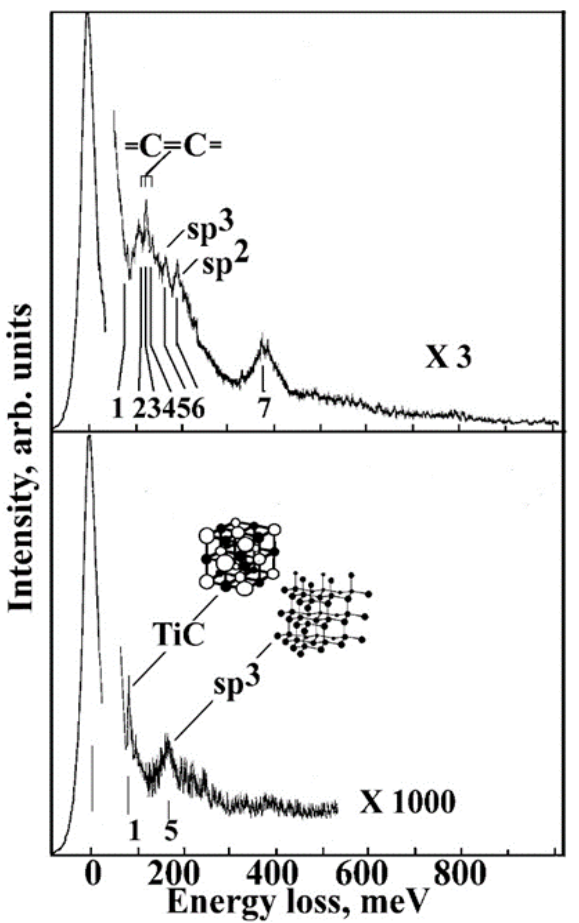

Fig.2- Spectres of TiC - ion-plasma coatings. formed with a reactive gas pressure of $1.06 \mathrm{~Pa}$ before (1) and after $900^{\circ} \mathrm{C}$ etching in $\mathrm{Ar}+(2)$

The intensities of the peaks of carbon and titanium carbide are determined depending on the kinetic energy. At a pressure of $0.004 \mathrm{~Pa}$, the carbon peaks in the composite nanostructured coating are not pronounced, which is clearly seen in Figure 1. The insufficient partial pressure of acetylene explains this in the vacuum chamber, i.e., first, the formation of a titanium carbide coating occurs, and then the carbon sublattice is filled. In the first case, with $\mathrm{TiCx}_{1} \cdot \mathrm{x}_{1}$ the content of titanium is in excess while the carbon content is not enough.

In the second case, with $\mathrm{TiCx}_{2}$, the crystal lattice of $\mathrm{TiCx}_{2}$ is distorted due to the embedded carbon atom, which, depending on the partial pressure of acetylene, affects the physical properties of the composite nanostructured coating.

Analysis of XPS lines C1 in Ti carbides shows the presence of carbon in the free state (Figure 1. 2). Based on experimental studies of composite nanostructured coatings based on $\mathrm{TiC}$, the $\mathrm{p}-\mathrm{T}-\mathrm{x}$ diagrams for $\mathrm{TiC}$ were refined. Composite nanostructured coatings of both stoichiometric and non-stoichiometric composition are formed on the diagrams of a wide range of acetylene pressure corresponding to the content of titanium and carbon. Free diamond-like carbon, the presence of which depends on the deposition condition.

Based on diagrams denoting the state and properties, together with the $\mathrm{p}-\mathrm{T}$-x diagram, it is possible to determine the optimal compositions of titanium carbide coatings and the corresponding technological modes for obtaining the selected composition through the gas pressure and the substrate temperature. 


\section{Conclusion}

1. It should be noted that the compositions were developed, and composite nanostructured coatings were investigated based on the comprehensive studies conducted.

2. Coatings based on $\mathrm{TiC}$ include stoichiometric and non-stoichiometric phases and diamond-like carbon. Carbon production depends on the deposition conditions. 3. Based on P-T-X diagrams, it can be determined the optimal deposition parameters: gas pressure $\mathrm{P}$ and substrate temperature $\mathrm{T}$. Such a description of the process parameters can be applied to a wide class of ion-plasma installations.

\section{References}

1. Kosolapova T.Ya. Carbides. - M.: Metallurgy. p 300. (1968)

2. Kiparisov S.S.. Levinsky Yu.V.. Petrov A.P. Titanium carbide: production. properties. application. - M.: Metallurgy.. p 216. (1987)

3. Makarenko A.G.. Samboruk A.A.. Ermoshkin A.A.. Borisenkova E.A. Selfpropagating high-temperature synthesis of titanium carbide and nitride from granulated charge, Procuring production in mechanical engineering. 3. pp. $42-48$. (2007)

4. Pat. 2175988 of the Russian Federation. IPC C 22 B 34,12. Method for producing titanium carbide, S.V. Aleksandrovsky. D.V. Lee. St. Petersburg State Mining Institute. G.V. Plekhanov. 2000110870, 02; Appl.A. 2.27.2000. publ. 11.20.2001. (2000)

5. Pat. 2149076 of the Russian Federation. IPC C 01 B31, 30. The method of producing powders of refractory compounds based on titanium, GP Shveykin. Institute of Solid State Uro RAS. 98117637,02; Claims 09,25,1998. publ. 05,20, (2000).

6. S.V. Mushkov. G.G. Semyannikov. L.M. Berdnikova. E.N. Pinaev, Pat. 2066700 of the Russian Federation. IPC C 01 B31,30. Method for producing titanium carbide, S.V. Aleksandrov- 38 Bulletin of Siberian State Industrial University. 1 (7).. Berezniki Titanium and Magnesium Plant. No. 93001453,02; Claims 1,11,1993. publ. 03,27,1996. (2014).

7. M.S. Prozorov. L.S. Popov. V.P. Petrenko. V.I. Ratnikov. Pat. RF. IPC C 01 B31,30. The method of producing titanium carbide,A.G. Merzhanov. V.A. Drozdenko. I.P. Borovinskaya. Institute of Structural Macrokinetics of the USSR Academy of Sciences. No. 4450193,02; Claims 06,28,1988. publ. 08.27.2003.

8. Electronic catalog of the Russian National Public Library for Science and Technology [Electronic resource], the database contains information on all types of literature received by the Russian National Public Library for Science and Technology. - Access mode: [www.ihim.uran.ru. 12,22,2013] (Handling Date: 12,28,2013). (2013)

9. Podred. I.M. Fedorchenko Properties of powders of metals. refractory compounds and sintered materials ,. - Kiev: Naukova Dumka. p 184. (1978)

10. Wear-resistant composite material, Academy of Sciences of the USSR Order of Lenin Siberian Branch of the Republican Engineering and Technical Center for the restoration and hardening of machine parts and mechanisms.- Tomsk. p 1. (1985).

11. Electronic catalog of the Russian National Public Library for Science and Technology [Electronic resource]: [http:,www.nbuv.gov.ua, portal, natural, Nn,2002_2009, statti ,vup25,25-1,03.pdf; December 17. 2013]. (2013).

12. S.V. Aleksandrovsky. V.M. Sizyakov. D.V. Limbo. Geylikman. A.Kh. Ratner Method of producing titanium carbonitride. Pat. 2175021 of the Russian Federation. IPC C 22 
B 34,12., St. Petersburg State Mining Institute. G.V. Plekhanov. No. 2000125114,02; Claims 04. 10.2000. publ. 10,20,2001. (2001)

13. S.V. Aleksandrovsky. S.V. Mushkov. G.G. Semyannikov. L.M. Berdnikov. Pat. 2089708 of the Russian Federation. IPC C 22 B 34,12. Method of producing titanium carbide, Joint Stock Company «AVISMA Titanium and Magnesium Works». No. 94035156,02; Claims 09.11.1994. publ. 02.27.1997. (1997).

14. Krasnokutsky Yu.I.. Vereshchaka V.G. Receiving refractory compounds in plasma. Kiev: Vishcha School. Head publishing house. p 200. (1987).

15. Ed. I.M. Fedorchenko. Powder metallurgy. Materials. technology. properties. applications: a reference, -Kiev: Naukova Dumka. P 624. (1985).

16. Blinkov I.V. Development of processes for the modification and production of dispersed materials in a pulsed plasma. Author. Dis. Doctor of Technical Sciences M. p 47 p. (2007)

17. Plasma-chemical synthesis of ultrafine powders and their use for the modification of metals and alloys. Ed. Mf Zhukova. - Novosibirsk: Science. Siberian Publishing Company of the Russian Academy of Sciences. 1995. - 344 p.

18. Plasma Chem [Electronic resource],NanoPowders; Webmaster PIXXL.WEBDESIGN. - Electronic data. - Berlin: Plasma Chem Gmbh. [2008]. Access mode: http:,www.Plasmachem.com. free (Request date: 01,25,2013). (2013).

19. Neomat nano powders [Electronic resource],Products. - Electronic data. - Salaspils: Neomat Co.. [2008]. - Access mode: http:,www.neomat.lv. free. (Date of appeal: 01.22.2013). (2013)

20. Nanoceramics Powders [Electronic resource], Hefei Kaier Nanotechnology \& Development htd. Co. - Electronic data. - Hefei Kaier Nanotechnology \& Development htd. Co.. [2008]. - Access mode: http:,www.hfkiln.com. free. (Request date: 11.03.2013). (2013)

21. NanoAmor. Nanostructured and Amorphous Materials. Inc. [Electronic resource]. Products. - Electronic data. - Houston: Nanostructured \& Amorphous Materials. Inc.. [2008]. - Access mode: http:,www.Nanoamor.com. free. (Date of appeal: 04,04,2013). (2013)

22. Reshetnikova S.N. The use of nanopowders of chemical compounds to improve the quality of hardware. Author. Dis. Ph.D. Krasnoyars. p 17. (2008)

23. Romanenko E.F. Improving the performance and surface quality of instrumental materials by electrophysical coatings and combined treatment. Author. Dis. Ph.D. Kursk. P 19. (2011).

24. Goldshmit Kh. Dj. Splavy vnedreniya. Per. C angl. T. 1. M.: Mir. p 424. (1971)

25. Fetisov G.P.. Karpman M.G.. Saydakhmedov R.Kh. Ionno-plazmennye nestekhiometricheskie pokrytiya na osnove nitridov I karbidov perekhodnykh metallov. - M.: MAI-PRINT. P 220. (2011)

26. Kovalev. A.I.. Wainstein. D.L.. Karpman. M.G.. Saidakhmedov. R.Kh. Experimental verification of $P-T-C$ diagrams for Ti-C and $\mathrm{Zr}-\mathrm{C} P V D$ coatings and determination of free carbon state by AES. XPS and HREELS methods. Surface and Interface Analysis. 36 (8). pp. 1174-1177. (2004) 